\title{
A ojos rectorales
}

\section{Antonio Largo Cabrerizo}

Rector de la Universidad de Valladolid

Hace ya más de dos décadas, en marzo de 1999, comenzaba la andadura de la Defensoría de la Comunidad Universitaria de la UVa bajo el mandato del Rector Sanz Serna (entonces, y hasta hace muy poco tiempo, Oficina del Defensor de la Comunidad Universitaria).

No fueron comienzos fáciles, ya que, aunque su creación fue acordada por el Claustro en abril de 1992, bajo la presidencia del Rector Tejerina, se demoró más de siete años la ocupación del puesto por el primer Defensor - Tomás Sánchez Giralda-, que fue el responsable de la puesta en marcha de este servicio, continuado luego por Pilar Abad, Eugenio Baraja y, en la actualidad, Milagros Alario.

La función principal asignada a la Defensoría en los Estatutos de la UVa, "la defensa y garantía de los derechos e intereses legítimos de los miembros de la comunidad universitaria", ha constituido, a lo largo de estas dos décadas, la labor discreta pero fundamental de la Defensoría. Una labor a la que se han ido añadiendo en la última década la participación en la aplicación del Protocolo de actuación en materia de prevención e inhibición del acoso en el ámbito laboral de la Universidad de Valladolid (2012), el Protocolo de prevención y actuación frente al acoso sexual y acoso por razón de sexo en el ámbito de la Universidad de Valladolid (2014), sustituidos desde 2019 por el Protocolo de actuación en materia de prevención e inhibición del acoso en el ámbito laboral y el Protocolo de prevención y actuación frente al acoso sexual y acoso por razón de sexo para el alumnado de la Universidad de Valladolid. A estas funciones, se suma la finalidad de contribuir a la mejora de la calidad y el buen funcionamiento de la Universidad, mediante el diagnóstico y la realización de Informes y Recomendaciones sobre problemas detectados a través de las actuaciones de la defensoría, dirigidos a las autoridades académicas responsables.

Temas como los tratados en los números precedentes de la Revista RUED@: el plagio y el fraude, las asignaturas con resultados anómalos, los procesos de anulación de matrícula, el papel de las Defensorías en la transparencia universitaria, la delimitación del derecho de libertad de cátedra o la Universidad ante la normativa de protección de datos, constituyen, sin duda, cuestiones relevantes en el quehacer diario de cualquier universidad. La reflexión pausada y crítica que se vierte en estas publicaciones, fruto, en buena parte, de los casos tratados en las Defensorías, de encuentros y jornadas de análisis y debate entre defensores/as y adjuntos, aportan, sin duda, una interesante perspectiva que ayuda a las autoridades académicas en la toma de decisiones y en la corrección de posibles disfunciones de procedimientos o normativos.

El presente número de RUED@ recoge los resultados de los Encuentros anuales de CEDU celebrados en León y Valladolid, en 2018 y 2019, así como alguna de las aportaciones realizadas en la Jornada técnica que, obligada por la situación del Estado de Alarma, se realizó de forma virtual en junio de 2020. 
Se incluyen, entre otras, cuestiones de gran calado en la gestión universitaria, como la situación y problemas de aplicación del Reglamento de Disciplina Académica de los Centros Oficiales de Enseñanza Superior (8 septiembre de 1954), y su incidencia en la desigualdad de trato entre estudiantes de diferentes universidades, una norma en proceso de necesaria derogación pero con problemas de sustitución por otra norma que ampare a las Universidades en su potestad sancionadora; las cautelas y miedos ante las represalias que autolimitan a los miembros de la comunidad universitaria (especialmente estudiantado), a la hora de denunciar problemas de abuso o mala gestión; el debate sobre en qué momento procedimental es más adecuada la intervención de las Defensorías en los procedimientos a resolver y, por supuesto, la siempre conflictiva cuestión de la desigualdad de género en las carreras profesionales, constituyen una muestra excelente de lo que las Defensorías pueden aportar al día a día del gobierno y la gestión universitaria. Todos ellos problemas candentes que se viven cotidianamente en las Defensorías y los Equipos Rectorales.

El debate y reflexión deben ir acompañados de una imprescindible capacidad de actuación para proponer soluciones y/o vías alternativas de funcionamiento, que puedan ser implementadas por las autoridades académicas. Todas estas funciones conllevan, sin duda, una cotidiana e intensa relación con todos los servicios de la Universidad y, especialmente, cpn sus responsables, tanto en los Equipos Rectorales como en los de Dirección de Centros.

Dado que la figura del Defensor no tiene capacidad ejecutiva, y sus posibilidades de gestión se basan en su capacidad de analizar y plantear los problemas de forma clara, así como de recomendar vías de actuación razonables, es obvio que el correcto funcionamiento exige un sistema de relaciones entre Rectorado y Defensoría basado en tres principios básicos: independencia, respeto y escucha.

Independencia que garantiza la libertad de pensamiento, incluso la discrepancia, y la opinión "desde fuera", lo que permite enfrentar posiciones si fuere necesario hasta conseguir un acuerdo de consenso.

Respeto, que es la base de las relaciones en igualdad y que garantiza la escucha y el intercambio de ideas como base del acuerdo.

La UVa, en las más de dos décadas de funcionamiento de su Defensoría, constituye un ejemplo de aplicación de estos principios. Desde los diferentes Rectorados que se han sucedido a lo largo de este período, así como desde los distintos equipos de la Oficina el Defensor, estos principios de independencia y respeto, escucha y buena sintonía han constituido las bases de funcionamiento de la relación entre ambos. Un hecho que pone de manifiesto el sólido anclaje de la Defensoría en la Universidad de Valladolid, más allá de las personas concretas que ocupen los cargos en cada momento. 